Extracting Lignin-SiO 2 Composites from Si-Rich Biomass to Prepare Si/C Anode Materials for Lithium ions Batteries

Yixin Li, ${ }^{a}$ Li Liu, ${ }^{\text {b c }}$ Xiaoyang Liu, ${ }^{\text {a }}$ Yi Feng, ${ }^{a}$ Beichen Xue, ${ }^{a}$ Liyun Yu, ${ }^{a}$ Lijie Ma, ${ }^{a}$ Yanchao Zhu, ${ }^{a}$ Yimin Chao, ${ }^{\mathrm{c}}$ Xiaofeng Wang ${ }^{*}$ a, c

${ }^{\text {a }}$ State Key Laboratory of Inorganic Synthesis and Preparative Chemistry, College of Chemistry, Jilin University, Changchun, China

${ }^{\mathrm{b}}$ Department of Chemistry, Northeast Normal University, Changchun 130024, China

${ }^{\mathrm{c}}$ School of Chemistry, University of East Anglia, Norwich Research Park, Norwich, NR4 7TJ, UK

${ }^{*}$ Corresponding author. State Key Laboratory of Inorganic Synthesis and Preparative Chemistry, College of Chemistry, Jilin University. 2699 Qianjin Street, Changchun, 130012, PR China.

E-mail addresses: wangxf103@jlu.edu.cn (X, Wang) 


\section{Extracting Lignin-SiO2 Composites from Si-Rich Biomass to Prepare Si/C Anode Materials for Lithium ions Batteries}

Yixin Li, ${ }^{a}$ Li Liu, ${ }^{\text {, c }}$ Xiaoyang Liu, ${ }^{a}$ Yi Feng, ${ }^{a}$ Beichen Xue, ${ }^{a}$ Liyun $Y u,{ }^{a}$ Lijie Ma, ${ }^{a}$ Yanchao Zhu, ${ }^{\text {a }}$ Yimin Chao, ${ }^{\mathrm{c}}$ Xiaofeng Wang ${ }^{\text {a, c }}$

${ }^{a}$ State Key Laboratory of Inorganic Synthesis and Preparative Chemistry, College of Chemistry, Jilin University, Changchun, China

${ }^{\mathrm{b}}$ Department of Chemistry, Northeast Normal University, Changchun 130024, China

${ }^{c}$ School of Chemistry, University of East Anglia, Norwich Research Park, Norwich, NR4 $7 \mathrm{TJ}, \mathrm{UK}$

*Corresponding author. State Key Laboratory of Inorganic Synthesis and Preparative Chemistry, College of Chemistry, Jilin University. 2699 Qianjin Street, Changchun, 130012, PR China.

E-mail addresses: wangxf103@jlu.edu.cn (X, Wang) 


\begin{abstract}
The comprehensive utilization of Si-rich biomass is restrained by macromolecular lignin and a large amount of ash. In this study, rice husks (RHs) are treated as a representative by alkali extraction and acid precipitation, and the obtained lignin-SiO 2 composite is modified by carbonazation, ball milling, magnesiothermic reduction and additives. Through these processes, a Si/C composite with excellent electrochemical properties is obtained and performs stable cycling performance with high specific capacity retention of $572 \mathrm{~mA} \mathrm{~h} \mathrm{~g}^{-1}$ at $1 \mathrm{~A} \mathrm{~g}^{-1}$ after 1000 cycles. This introduced method provides a potential for utilizing Si-rich biomass comprehensively and preparing desirable $\mathrm{Si} / \mathrm{C}$ anode materials from $\mathrm{Si}$-rich biomass derived lignin-SiO 2 composites.
\end{abstract}

Keywords: Si-rich biomass; Alkali extraction; Lignin-SiO ${ }_{2}$ composites; $\mathrm{Si} / \mathrm{C}$ anode materials 


\section{Introduction}

Lignin is one of the components in the biomass mainly composed of lignocellulose [1-3]. Different with hemicellulose and cellulose, lignin possesses complicated three-dimensional net structures, which consist of three phenylpropane units connected by ether bonds and carbon-carbon bonds [4-6]. The aryl macromolecules with various linear branches and complicated structures result in inhomogeneous properties, and further restrict the application of lignin in the biomass industrial fields. Since the aryl macromolecules could be degraded into graphite-like carbon with high yield and the various linear branches tend to vaporize as small hydrocarbon molecules [7-9], lignin was pyrolyzed into high-valued carbon by many researchers to eliminate the inhibitions of the inhomogeneous properties, and the expanded utilization of lignin may be realized in the biomass industrial.

Until now, lignin-derived carbon was always utilized as electrodes for supercapacitors and lithium ions batteries (LIBs), which are both reliable energy storage devices [10-12], and many researches manifest that lignin-derived carbon is suitable as anode materials for LIBs due to its unique disordered turbostratic structures [13-18]. Chang et al [19] carbonized lignin at $800{ }^{\circ} \mathrm{C}$ with the assistance of $\mathrm{H}_{2}$ reduction, and the specific capacity of obtained carbon reached $228 \mathrm{~mA} \mathrm{~h} \mathrm{~g}^{-1}$ after 200 cycles at a current density of $0.74 \mathrm{~A} \mathrm{~g} \mathrm{~g}^{-1}$. Zhao et al [20] prepared lignin-derived nitrogen-doped carbon nanospheres, whose specific capacity kept at $225 \mathrm{~mA} \mathrm{~h} \mathrm{~g}^{-1}$ after 50 cycles at $60 \mathrm{~mA} \mathrm{~g}^{-1}$. 
Hence, the lignin-derived carbon performs desirable electrochemical properties as anode materials for LIBs, which results in promising applications among various carbon-based materials. However, with the rapid growing demands of high power LIBs, the researches on $\mathrm{Si} / \mathrm{C}$ anode materials are increasing in recent years [21-25]. Lignin has a desirable application prospect in this field, which could serve as carbon source for $\mathrm{Si} / \mathrm{C}$ anode materials, but there are few studies in this aspect.

In the Si-rich biomass, most silicate exists in the secondary wall of cells and attaches lignin compactly, forming the multi-layers with channels to prevent the harm of bacteria and injurious insects, as well as absorb the nutrients [26-28]. The commensal lignin and silicate possess similar hydrolytic properties, which can be solved by alkaline solution and precipitated by acidic solution [29, 30]. Xue et al. [31] obtained lignin- $\mathrm{SiO}_{2}$ hybrid composite with spherical morphology from $\mathrm{RHs}$ with $\mathrm{NaOH}$ dissolving, followed by $\mathrm{H}_{2} \mathrm{SO}_{4}$ precipitating. With a series of physical and chemical treatments, the biomass-derived lignin- $\mathrm{SiO}_{2}$ composites could be translated into $\mathrm{Si} / \mathrm{C}$ anode materials for LIBs.

In this study, RHs derived lignin-silicate composite was dissolved into $\mathrm{NaOH}$ solution and followed by adjusting $\mathrm{pH}$ with $\mathrm{H}_{2} \mathrm{SO}_{4}$ to obtain lignin- $\mathrm{SiO}_{2}$ composite with core-shell structure. The composite was modified by a series of physical and chemical treatments to prepare $\mathrm{Si} / \mathrm{C}$ anode materials for LIBs with promoted electrochemical properties. The biomass derived lignin-silicate composites show promising applications 
in LIBs and the study may provide a new strategy to utilize the biomass derived lignin-silicate efficiently.

\section{Material and methods}

\subsection{Materials}

RHs were obtained from the rice mill around Changchun City, China. Sodium hydroxide, sulfuric acid, hydrofluoric acid, hydrochloric acid and graphite powder (325 mesh) were all purchased from Sinopharm Chemical Reagent Beijing Co. Ltd, and polyethylene glycol-2000 (PEG-2000) was purchased from Guangfu Chemical Reagent Corporation. Mg powder was purchased from Aladdin Industrial Corporation and coal tar electrode pitch (CTEP) was purchased from Chaolian new materials Co., Ltd of Shandong Province. All the reagents above are of analytical grade. Electrode shells, lithium foils, copper foils, electrode separators, electrolyte, cell connectors and gaskets used for CR2025 coin cells were purchased from Hefei Kejing Materials Technology Co., Ltd of Anhui Province.

2.2 Preparation of lignin-silica composites (LS and $p$-LS)

\subsubsection{Preparation of LS}

$50 \mathrm{~g}$ washed and pulverized RHs were dipped into $500 \mathrm{~mL} 1 \mathrm{M} \mathrm{HCl}$ at first. The residue was extracted by vacuum filtration and added into $350 \mathrm{~mL} 8 \% \mathrm{NaOH}$ solution, followed by boiling the mixture with reflux for $4 \mathrm{~h}$. Afterwards, the solution was extracted by vacuum filtration and mixed with deionized water and ethanol with a 
volume ratio of 2:1:1. Subsequently, $1 \mathrm{M} \mathrm{H}_{2} \mathrm{SO}_{4}$ was dropped into the solution continually under magnetic stirring and 5 g PEG-2000 was added when the sediment started to appear. Until $\mathrm{pH}=3$, the mixture was laid for $30 \mathrm{~min}$, followed by vacuum filtration, and the filtrate residue was washed to neutral by deionized water. After drying at $100{ }^{\circ} \mathrm{C}$ overnight, the lignin- $\mathrm{SiO}_{2}$ composite extracted by alkaline solution was obtained and marked as LS.

\subsubsection{Preparation of $p$-LS}

$10 \mathrm{~g} \mathrm{RH}$ was added to $100 \mathrm{~mL} 72 \% \mathrm{H}_{2} \mathrm{SO}_{4}$ and the mixture was magnetic stirred in a $50{ }^{\circ} \mathrm{C}$ water bath for $5 \mathrm{~min}$, followed by vacuum filtration. The filtrate residue was washed to neutral by deionized water. After drying at $100{ }^{\circ} \mathrm{C}$ overnight, the acid precipitated lignin/silica composite was obtained and marked as $p$-LS.

\subsection{Carbonization and ball-milling}

LS was put in a porcelain boat and carbonized in a quartz tube furnace at $700{ }^{\circ} \mathrm{C}$ for $2 \mathrm{~h}$ under Ar with a heating rate of $5{ }^{\circ} \mathrm{C} \mathrm{min}^{-1}$, followed by cooling to room temperature naturally. Afterwards, $1.0 \mathrm{~g}$ of the carbonized LS was loaded into zirconia jars, which contained $90 \mathrm{~g}$ zirconia balls with inhomogenous size. After $6 \mathrm{~h}$ ball-milling at $800 \mathrm{rpm}$, the product was obtained and denoted as LS-B. For comparison, $p$-LS was carbonized and ball-milled under the same conditions and the product was denoted as $p$-LS-B.

\subsection{Magnesiothermic reduction}

The content of silica was realized according to the TG curves in Figure 1a. $0.5 \mathrm{~g}$ of 
LS-B (containing $0.39 \mathrm{~g} \mathrm{SiO}_{2}$ ) was ground with $0.33 \mathrm{~g} \mathrm{Mg}$ powder in an argon-filled glove box and the mixture was loaded in a porcelain boat, followed by paving $4.15 \mathrm{~g} \mathrm{KCl}$ and $4.15 \mathrm{~g} \mathrm{LiCl}$. Afterwards, the porcelain boat was put in a quartz tube furnace and calcined at $650{ }^{\circ} \mathrm{C}$ for $5 \mathrm{~h}$ with a heating rate of $5{ }^{\circ} \mathrm{C} \mathrm{min}^{-1}$. After cooling to room temperature naturally, the product was washed by $1 \mathrm{M} \mathrm{HCl}$ for $5 \mathrm{~h}$ and $1 \mathrm{M} \mathrm{HF}$ for 20 min respectively, followed by washing to neutral by deionized water and drying at $80{ }^{\circ} \mathrm{C}$ in a vacuum oven overnight. The obtained product was denoted as LS-BM. As a contrast, $0.5 \mathrm{~g}$ of $p$-LS-B (containing $0.33 \mathrm{~g} \mathrm{SiO}_{2}$ ) was conducted a magnesiothermic reduction with $0.28 \mathrm{~g} \mathrm{Mg}$ powder, followed by paving salt mixture of $3.9 \mathrm{~g} \mathrm{KCl}$ and $3.9 \mathrm{~g} \mathrm{LiCl}$. Other conditions remained the same as that of LS-B and the product was denoted p-LS-BM.

\subsection{Additives modification}

$0.09 \mathrm{~g}$ of the LS-BM, $0.015 \mathrm{~g}$ CTEP and $0.015 \mathrm{~g}$ graphite were dispersed into $80 \mathrm{~mL}$ ethanol and magnetic stirred for $2 \mathrm{~h}$, followed by vacuum filtration. The filtrate residue was washed with $80 \mathrm{~mL}$ ethanol for 3 times and dried at $80{ }^{\circ} \mathrm{C}$ overnight. Afterwards, the dried filtrate residue was calcined at $120{ }^{\circ} \mathrm{C}$ for $1 \mathrm{~h}$ in a nitrogen-filled quartz tube furnace, and continually calcined at $850{ }^{\circ} \mathrm{C}$ for $3 \mathrm{~h}$ with a heating rate of $5{ }^{\circ} \mathrm{C} \min ^{-1}$, followed by cooling to room temperature naturally. Meanwhile, $p$-LS-BM was modified with CTEP and graphite under the same conditions. The additives modified materials were denoted as LS-BMA and $p$-LS-BMA respectively. The preparation mechanism from 


\subsection{Characterization}

The thermogravimetric analysis (TGA) was tested by TGA Q500 thermogravimetric analyzer, heating at a rate of $10{ }^{\circ} \mathrm{C} \mathrm{min}^{-1}$ at air atmosphere. The $\mathrm{X}$-ray photoelectron spectroscopy (XPS) was performed by ESCALAB250 X-ray photoelectron spectrometer. The morphologies of products were examined by a field emission scanning electron microscope (SEM, JSM-6700F, Japan) and transmission electron microscope (TEM, Tecnai G2 S-Twin F20, Netherlands). Raman spectra (INVIA, England) were obtained from 100 to $3200 \mathrm{~cm}^{-1}$ with a He-Ne laser at the wavelength of $532 \mathrm{~nm}$. The D/MAX2550 X-ray diffractometer was used to characterize the existence and the structure of crystalline silicon and the ASAP 2420 surface area analyzer was used at $77 \mathrm{~K}$ with the Brunauer-Emmett-Teller (BET) method to obtain nitrogen adsorption and desorption isotherms.

\subsection{Electrochemical measurements}

CR2025 coin cells were assembled, which were used to evaluate the electrochemical performance of LS-BM, LS-BMA, $p$-LS-BM and $p$-LS-BMA. The active material (80 $\mathrm{wt} \%$ ), conductive material (acetylene black) (10 wt \%) and binder (polyvinylidene fluoride) (10 wt $\%$ ) were mixed and compressed onto a copper foil, as well as dried at $80{ }^{\circ} \mathrm{C}$ in a vacuum oven overnight. The copper foil with the composite was punched into wafers as the anode, whose diameter was $1.2 \mathrm{~cm}$ and the mass loading of active materials was 
$0.8-1.2 \mathrm{mg} \mathrm{cm}^{-2}$. Serving the single-layer metal lithium foil as the counter electrode, Celgard 2500 separator as the separator, and $1 \mathrm{M} \mathrm{LiPF}_{6}$ in EC:EMC:DMC $(1: 1: 1, \mathrm{v} / \mathrm{v} / \mathrm{v})$ as the electrolyte, the CR2025 coin cells were assembled in an argon-filled glove box. Electrochemical measurements were carried out after laying the assembled coin cells aside for $10 \mathrm{~h}$. The Neware CT-4008W battery test system was used to perform galvanostatic charge-discharge measurement from 0.01 to $3.0 \mathrm{~V}$ (vs. $\mathrm{Li} / \mathrm{Li}+$ ) at a current density of $0.1 \mathrm{~A} \mathrm{~g} \mathrm{~g}^{-1}$ and $1 \mathrm{~A} \mathrm{~g}^{-1}$ and rate performance at various current densities from 0.1 to $5 \mathrm{~A} \mathrm{~g}^{-1}$. CHI 760D electrochemical workstation was used to collect cyclic voltammetry curves from $0.01 \mathrm{~V}$ to $3 \mathrm{~V}$ at a sweeping rate of $0.01 \mathrm{~V} \mathrm{~s}^{-1}$, as well as electrochemical impedance spectroscopy (EIS), which was carried out at open circuit potential from 100 $\mathrm{kHz}$ to $0.01 \mathrm{~Hz}$ with an amplitude of $10 \mathrm{mV}$.

\section{Results and discussion}

TG curves are shown in Figure 2a to realize the content of each component in the four samples. $10 \%$ more weight of $p$-LS-B was lost than LS-B, because the cellulose was dehydrated to various carbon-based products by $72 \% \mathrm{H}_{2} \mathrm{SO}_{4}$. Some of these products were retained in the sediment and participated in the subsequent pyrolyzation, leading to a higher carbon content [32]. The remained weight of LS-BM is $67.64 \%$ and significantly different from the low ash content of $p$-LS-BM as $19.01 \%$, indicating that a large proportion of $\mathrm{SiO}_{2}$ was etched by $\mathrm{HF}$ and low content of $\mathrm{Si}$ was generated in $p$-LS-BM. The low content of Si in $p$-LS-BM could be attributed to the unbreakable carbon coating 
in $p$-LS-B formed by the natural cross-linked lignin macromolecules, hindering the contact of $\mathrm{SiO}_{2}$ and $\mathrm{Mg}$ powder. For $\mathrm{LS}$, the macromolecules of lignin were degraded into short fragments in alkaline solution [31], and the carbon coating was broken up through ball-milling to facilitate the magnesiothermic reduction.

XRD patterns are presented in Figure $2 \mathrm{~b}$ to show the transition of the reactants after magnesiothermic reduction. The broad peaks at $23^{\circ}$ indicate $\mathrm{C} / \mathrm{SiO}_{2}$ composites are all amorphous [33]. Three sharp peaks at $28.4^{\circ}, 47.4^{\circ}$ and $56.2^{\circ}$ of LS-BM appear, which are assigned to the (111), (220) and (311) crystal planes of cubic Si. Combined with the XRD pattern of Figure S2, these three sharp peaks could confirm the occurrence of the reactions as follows [33-35].

$$
\begin{aligned}
& \mathrm{SiO}_{2}+2 \mathrm{Mg} \rightarrow 2 \mathrm{MgO}+\mathrm{Si} \\
& \mathrm{SiO}_{2}+2 \mathrm{MgO} \rightarrow \mathrm{Mg}_{2} \mathrm{SiO}_{4}
\end{aligned}
$$

While no sharp peak is presented in $p$-LS-BM, indicating no crystal phase of silicon is excited, which is consistent with the results of TG curves. Therefore, LS-BM has more content of $\mathrm{Si}$ and could be used as a $\mathrm{Si} / \mathrm{C}$ anodes material for LIBs.

The morphologies of all samples can be observed from SEM images. As shown in Figure S3, the coated $\mathrm{SiO}_{2}$ spheres are obvious in the LS samples, but not in the $p$-LS samples. After ball-milling, carbon bulks are visible in the sample $p$-LS-B (Figure 3d), while carbon bulks and scattered $\mathrm{SiO}_{2}$ spheres are shown in the LS-B sample (Figure 3a). This morphology is more advantageous for the contact of $\mathrm{SiO}_{2}$ particles and $\mathrm{Mg}$ powder 
to facilitate the magnesiothermic reduction. After magnesiothermic reduction, the retained oxides $\left(\mathrm{MgO}\right.$ and $\left.\mathrm{SiO}_{2}\right)$ were etched by acid and porous structures were generated (Figure 3b and 3e), which could facilitate ionic diffusion and electronic transportation [36]. In addition, the lattice fringes of $0.31 \mathrm{~nm}$, corresponding to the (111) crystal plane of cubic Si, are shown in the HRTEM of LS-BM (Figure 3c), but not in $p$-LS-BM (Figure 3f). The lattice fringes were distributed around by the amorphous carbon, which could enhance cycling performance of LS-BM.

To verify the variation of $\mathrm{SiO}_{2}$, XPS spectra of $\mathrm{Si} 2 \mathrm{p}$ are shown in Figure 4. It can be seen in Figure 4a that the peak of $\mathrm{SiO}_{2}(103.6 \mathrm{eV})$ of $\mathrm{LS}-\mathrm{B}$ is stronger than that of $p$-LS-B, indicating the content of $\mathrm{SiO}_{2}$ on the surface of LS-B is much higher. In Figure $4 \mathrm{~b}$, the peak of $\mathrm{Si}(99.1 \mathrm{eV})$ of LS-BM is stronger than that of $p$-LS-BM, which indicates that the magnesiothermic reduction of LS-B proceeded more completely. Raman spectra are shown to prove the results shown by XPS spectra. The two peaks at $503 \mathrm{~cm}^{-1}$ and 926 $\mathrm{cm}^{-1}$ are observed in Figure $4 \mathrm{c}$, which represent the Raman peaks of Si, but not observed in Figure 4d. The comparison of Raman spectra could confirm the generation of Si in LS-BM, contributing for high specific capacity as anodes for LIBs.

Galvanostatic charge-discharge (GCD) profiles are shown in Figure 5. At the current density of $0.1 \mathrm{~A} \mathrm{~g} \mathrm{~g}^{-1}$, LS-BM possesses first discharge specific capacity of $2560 \mathrm{~mA} \mathrm{~h} \mathrm{~g}^{-1}$ with the ICE of 44\%. The low ICE of LS-BM is caused by the large specific surface area (SSA), which is confirmed by pore size distributions shown in Figure S4c. The SSA 
increases from $52.74 \mathrm{~m}^{2} \mathrm{~g}^{-1}$ (LS-B) to $466.57 \mathrm{~m}^{2} \mathrm{~g}^{-1}$ (LS-BM), and the solid electrolyte interface (SEI) film is formed in a large scale, which results in huge consumption of lithium ions and a low ICE at first cycle [37-41]. For $p$-LS-BM, the first discharge specific capacity displays as high as $1982 \mathrm{~mA} \mathrm{~h} \mathrm{~g}^{-1}$, which could be ascribed to the porous structure formed by HF etching, providing more active sites for lithium ions to embed in $[42,43]$. The low ICE $(38 \%)$ of $p$-LS-BM is caused by the increase of SSA from $24.4394 \mathrm{~m}^{2} \mathrm{~g}^{-1}\left(p\right.$-LS-B) to $447.18 \mathrm{~m}^{2} \mathrm{~g}^{-1}$ ( $p$-LS-BM). After additives modification, the ICE of LS-BMA and p-LS-BMA increases to 55\% and 53\% respectively, because the additives could fill a portion of pores and the SSA decreases to $316.77 \mathrm{~m}^{2} \mathrm{~g}^{-1}$ and 229.52 $\mathrm{m}^{2} \mathrm{~g}^{-1}$ respectively. It is worthwhile noted that a long discharge voltage plateau between 0-0.2 V and a charge voltage plateau between 0.3-0.6 V appear in Figure 5a and 5b, corresponding to the alloy of $\mathrm{Si}$, and dealloy of $\mathrm{Li}_{\mathrm{x}} \mathrm{Si}$ respectively. However, the plateaus in GCD profiles of LS-BM shrink as the cycles increase and almost vanish after 100 cycles, while the plateaus in GCD profiles of LS-BMA keep stable and even exist after 1000 cycles at $1 \mathrm{~A} \mathrm{~g} \mathrm{~g}^{-1}$, indicating the additives assist the material to improve cycling performance.

Capacity differential profiles are presented in Figure 6 to prove the electrochemical reactions during the charge/discharge process. A reduction peak at about $1.13 \mathrm{~V}$ exists in all materials, assigned to the formation of SEI film. Two oxidation peaks at $0.36 \mathrm{~V}, 0.52$ $\mathrm{V}$, and a reduction peak at $0.2 \mathrm{~V}$ are presented in LS-BM and LS-BMA, corresponding to 
the alloy and dealloy of $\mathrm{Li}_{\mathrm{x}} \mathrm{Si}$ respectively [40]. In addition, the peaks of LS-BM become weaker as the cycle number increases, while the peaks of LS-BMA keep stable, suggesting the stabilizing effect of the additives on cycling performance.

Cycling performances at a current density of $1 \mathrm{~A} \mathrm{~g}^{-1}$ are presented in Figure 7. $p$-LS-BM possesses a stable cycling performance, with the specific capacity retention of $482 \mathrm{~mA} \mathrm{~h} \mathrm{~g}^{-1}$, double that of $p$-LS-BMA approximately, because the additives have blocking effects on the active sites of carbon-dominated materials, lowering specific capacity of $p$-LS-BMA contrarily. For LS-BM, the specific capacity fades consistently in 100 cycles and tends to be steady after 100 cycles. Compared with S-BM in Figure S6, the specific capacity of S-BM fades dramatically from $3168 \mathrm{~mA} \mathrm{~h} \mathrm{~g}^{-1}$ to $40 \mathrm{~mA} \mathrm{~h} \mathrm{~g}^{-1}$ in 10 cycles, indicating that the lignin-derived carbon could buffer part of the volume expansion of Si. The specific capacity of LS-BMA presents a slight decay in 10 cycles and followed by a stable cycling performance until termination. After 1000 cycles, LS-BMA displays a specific capacity retention of $572 \mathrm{~mA} \mathrm{~h} \mathrm{~g}^{-1}$ at $1 \mathrm{~A} \mathrm{~g}^{-1}$, compared to $137 \mathrm{~mA} \mathrm{~h} \mathrm{~g}^{-1}$ of LS-BM, indicating that the additives could effectively control the volume expansion of Si and promote cycling performance.

Rate performances at current densities from $0.1 \mathrm{~A} \mathrm{~g}^{-1}$ to $5 \mathrm{~A} \mathrm{~g}^{-1}$ are displayed in Figure 8. The values of initial reversible specific capacity at $0.1 \mathrm{~A} \mathrm{~g}^{-1}$ of LS-BM, LS-BMA, $p$-LS-BM and $p$-LS-BMA are $1191 \mathrm{~mA} \mathrm{~h} \mathrm{~g}^{-1}, 750 \mathrm{~mA} \mathrm{~h} \mathrm{~g}^{-1}, 1027 \mathrm{~mA} \mathrm{~h} \mathrm{~g}^{-1}$ and $607 \mathrm{~mA} \mathrm{~h} \mathrm{~g}^{-1}$, respectively. As the current density increases, the curves present 
typical stairs. At $5 \mathrm{~A} \mathrm{~g}^{-1}$, the values of specific capacity turn down to $220 \mathrm{~mA} \mathrm{~h} \mathrm{~g}{ }^{-1}$, $297 \mathrm{~mA} \mathrm{~h} \mathrm{~g}^{-1}, 181 \mathrm{~mA} \mathrm{~h} \mathrm{~g}^{-1}$ and $149 \mathrm{~mA} \mathrm{~h} \mathrm{~g}^{-1}$, respectively. When the current density is restored to $0.1 \mathrm{~A} \mathrm{~g}^{-1}$, the specific capacities of LS-BMA and $p$-LS-BMA recover to 878 $\mathrm{mA} \mathrm{h} \mathrm{g}^{-1}$ and $483 \mathrm{~mA} \mathrm{~h} \mathrm{~g}^{-1}$, while LS-BM and $p$-LS-BM show the capacity retention of $650 \mathrm{~mA} \mathrm{~h} \mathrm{~g}^{-1}$ and $550 \mathrm{~mA} \mathrm{~h} \mathrm{~g}^{-1}$. Compared with the retained capacity at 35 cycles in Figure S5, it could be calculated out that LS-BM suffers a capacity loss of $330 \mathrm{~mA} \mathrm{~h} \mathrm{~g}^{-1}$ after cycling at higher densities, as well as $100 \mathrm{~mA} \mathrm{~h}^{-1}$ for $p$-LS-BM. These results confirm that the additives reinforced the structure of the materials and prevented the electrode from being damaged under a high current density.

\section{Conclusions}

In summary, a lignin- $\mathrm{SiO}_{2}$ composite was obtained from $\mathrm{RHs}$ by alkali extraction and acid precipitation, due to the similar hydrolytic properties of lignin and silicate in Si-rich biomass. The lignin-SiO 2 composite was modified by carbonazation, ball milling, magnesiothermic reduction and additives, and the $\mathrm{Si} / \mathrm{C}$ composite with excellent electrochemical properties was obtained, which exhibited enhanced cycling performance and high specific capacity (572 $\mathrm{mA} \mathrm{h} \mathrm{g}^{-1}$ at $1 \mathrm{~A} \mathrm{~g}^{-1}$ after 1000 cycles) as anode materials for LIBs. With the technique, the biomass derived lignin-silicate composites can be applied into LIBs efficiently and the comprehensive utilization of Si-rich biomass can be realized.

\section{Acknowledgements}


This work was supported by Graduate Innovation Fund of Jilin University (No. 101832018C176).

\section{Appendix A. Supplementary data}

\section{References}

[1] J. Xu, L. Dai, Y. Gui, L. Yuan, C. Zhang, Y. Lei, Synergistic benefifits from a lignin-fifirst biorefifinery of poplar via coupling acesulfamate ionic liquid followed by mild alkaline extraction, Bioresour. Technol. $303 \quad$ (2020) 122888. https://doi.org/10.1016/j.biortech.2020.122888.

[2] L. Wang, H. Ni, J. Zhang, Q. Shi, R. Zhang, H. Yu, M. Li, Enzymatic treatment improves fast pyrolysis product selectivity of softwood and hardwood lignin, Sci. Total Environ.717 (2020) 137241. https://doi.org/10.1016/j.scitotenv.2020.137241.

[3] K. Kohli, S. Katuwal, A. Biswas, B.K. Sharma, Effective delignifification of lignocellulosic biomass by microwave assisted deep eutectic solvents, Bioresour. Technol.303 (2020) 122897. https://doi.org/10.1016/j.biortech.2020.122897.

[4] O. Rosales-Calderon, V. Arantes, A review on commercial-scale high-value products that can be produced alongside cellulosic ethanol, Biotechnol. Biofuels 12 (2019) 240. https://doi.org/10.1186/s13068-019-1529-1. 
[5] J. Deng, T. Xiong, H. Wang, A. Zheng, Y. Wang, Effects of Cellulose, Hemicellulose, and Lignin on the structure and morphology of porous carbons, ACS Sustain. Chem. Eng. 4 (2016) 3750-3756. https://doi.org/10.1021/acssuschemeng.6b00388.

[6] E.D. Gomes, A.E. Rodrigues, Recovery of vanillin from kraft lignin depolymerization with water as desorption eluent, Sep. Purif. Technol. 239 (2020) 116551. https://doi.org/10.1016/j.seppur.2020.116551.

[7] R.K. Sharma, J.B. Wooten, V.L. Baliga, X. Lin, W.G. Chan, M.R. Hajaligol, Characterization of chars from pyrolysis of lignin, Fuel 83 (2004) 1469-1482. https://doi.org/10.1016/j.fuel.2003.11.015.

[8] T. Saito, R.H. Brown, M.A. Hunt, D.L. Pickel, J.M. Pickel, J.M. Messman, F.S. Baker, M. Keller, A.K. Naskar, Turning renewable resources into value-added polymer: development of lignin-based thermoplastic, Green Chem. 14 (2012) 3295. https://doi.org/10.1039/c2gc35933b.

[9] W.E. Tenhaeff, O. Rios, K. More, M.A. McGuire, Highly robust lithium ion battery anodes from lignin: an abundant, renewable, and low-cost material, Adv. Funct. Mater. 24 (2014) 86-94. https://doi.org/10.1002/adfm.201301420.

[10] C. Jing, X. Song, K. Li, Y. Zhang, X. Liu, B. Dong, F. Dong, S. Zhao, H. Yao, Y. Zhang, Optimizing the rate capability of nickel cobalt phosphide nanowires on graphene oxide by the outer/inter-component synergistic effects, J. Mater. Chem. A 8 (2020) 1697-1708. https://doi.org/10.1039/c9ta12192g. 
[11] C. Jing, X. Dong, K. Li, X. Liu, B. Dong, F. Dong, Y. Zhang, The pseudocapacitance mechanism of graphene/CoAl LDH and its derivatives: Are all the modififications $\begin{array}{llllll}\text { benefificial? } & \text { J. } & \text { Energy } & \text { Chem. } & 52 & \text { (2021) }\end{array}$ https://doi.org/10.1016/j.jechem.2020.04.019.

[12] C. Jing, X. Guo, L. Xia, Y. Chen, X. Wang, X. Liu, B. Dong, F. Dong, S. Li, Y. Zhang, Morphologically confifined hybridization of tiny CoNi2S4 nanosheets into S, P co-doped graphene leading to enhanced pseudocapacitance and rate capability, Chem. Eng. J. 379 (2020) 122305. https://doi.org/10.1016/j.cej.2019.122305.

[13] S. Chatterjee, E.B. Jones, A.C. Clingenpeel, A.M. McKenna, O. Rios, N.W. McNutt, D.J. Keffer, A. Johs, conversion of lignin precursors to carbon fibers with nanoscale graphitic domains, Adv. Funct. Mater. 2 (2014) 2002-2010. https://dx.doi.org/10.1021/sc500189p.

[14] D. Saha, Y. Li, Z. Bi, J. Chen, J.K. Keum, D.K. Hensley, H.A. Grappe, H.M. Meyer, III, S. Dai, M.P. Paranthaman, A.K. Naskar, Studies on supercapacitor electrode material from activated lignin-derived mesoporous carbon, Langmuir 30 (2014) 900-910. https://dx.doi.org/10.1021/la404112m.

[15] Z. Chang, B. Yu, C. Wang, Lignin-derived hierarchical porous carbon for high-performance supercapacitors, J. Solid State Electrochem. 20 (2016) 1405-1412. https://doi.org/10.1007/s10008-016-3146-2. 
[16] S. Wang, L. Yang, L.P. Stubbs, X. Li, C. He, Lignin-derived fused electrospun carbon fibrous mats as high performance anode materials for lithium ion batteries, ACS Appl. Mater. Interfaces 5 (2013) 12275-12282. https://dx.doi.org/10.1021/am4043867.

[17] Y. Li, Y. Huang, K. Song, X. Wang, K. Yu, C. Liang, Rice husk lignin- derived porous carbon anode material for lithium- ion batteries, ChemistrySelect 4 (2019) 4178-4184. https://doi.org/10.1002/slct.201900401.

[18] K. Yu, T. Liu, Q. Zheng, X. Wang, W. Liu, J. Liang, C. Liang, Rice husk lignin-based porous carbon and $\mathrm{ZnO}$ composite as an anode for high-performance lithium-ion batteries, J. Porous Mat. $27 \quad$ (2020) 875-882. https://doi.org/10.1007/s10934-019-00824-9.

[19] Z. Chang, B. Yu, C. Wang, Influence of $\mathrm{H}_{2}$ reduction on lignin-based hard carbon performance in lithium ion batteries, Electrochim. Acta 176 (2015) 1352-1357. http://dx.doi.org/doi:10.1016/j.electacta.2015.07.076.

[20] H. Zhao, Q. Wang, Y. Deng, Q. Shi, Y. Qian, B. Wang, L. Lv, X. Qiu, Preparation of renewable lignin-derived nitrogen-doped carbon nanospheres as anodes for lithium-ion batteries, RSC Adv. 6 (2016) 77143-77150. https://DOI: 10.1039/C6RA17793J.

[21] H. Jia, J. Zheng, J. Song, L. Luo, R. Yi, L. Estevez, W. Zhao, R. Patel, X. Li, J.-G. Zhang, A novel approach to synthesize micrometer-sized porous silicon as a high performance anode for lithium-ion batteries, Nano Energy 50 (2018) 589-597. https://doi.org/10.1016/j.nanoen.2018.05.048. 
[22] X. Zuo, X. Wang, Y. Xia, S. Yin, Q. Ji, Z. Yang, M. Wang, X. Zheng, B. Qiu, Z. Liu, J. Zhu, P. Müller-Buschbaum, Y.-J. Cheng, Silicon/carbon lithium-ion battery anode with 3D hierarchical macro-/mesoporous silicon network: Self-templating synthesis via magnesiothermic reduction of silica/carbon composite, J. Power Sources 412 (2019) 93-104. https://doi.org/10.1016/j.jpowsour.2018.11.039.

[23] D.P. Wong, R. Suriyaprabha, R. Yuvakumar, V. Rajendran, Y.-T. Chen, B.-J. Hwang, L.-C. Chen, K.-H. Chen, Binder-free rice husk-based silicon-graphene composite as energy efficient Li-ion battery anodes, J. Mater. Chem. A 2 (2014) 13437-13441. https://doi.org/10.1039/c4ta00940a.

[24] Y. Shen, Rice Husk Silica-Derived Nanomaterials for battery applications: a literature review, J. Agric. Food Chem. 65 (2017) 995-1004. https://doi.org/10.1021/acs.jafc.6b04777.

[25] Y. Zhang, Y. You, S. Xin, Y. Yin, J. Zhang, P. Wang, X. Zheng, F. Cao, Y. Guo, Rice husk-derived hierarchical silicon/nitrogen-doped carbon/carbon nanotube spheres as low-cost and high-capacity anodes for lithium-ion batteries, Nano Energy 25 (2016) 120-127. http://dx.doi.org/10.1016/j.nanoen.2016.04.043.

[26] D.S. Jung, M.H. Ryou, Y.J. Sung, S.B. Park, J.W. Choi, Recycling rice husks for high-capacity lithium battery anodes, Proc. Natl. Acad. Sci. U. S. A. 110 (2013) 12229-12234. https://doi.org/10.1073/pnas.1305025110. 
[27] W. Wang, J.C. Martin, N. Zhang, C. Ma, A. Han, L. Sun, Harvesting silica nanoparticles from rice husks, J. Nanopart. Res. 13 (2011) 6981-6990. https://doi.org/10.1007/s11051-011-0609-3.

[28] Y. Shen, Rice husk silica derived nanomaterials for sustainable applications, Renew. Sust. Energ. Rev. 80 (2017) 453-466. http://dx.doi.org/10.1016/j.rser.2017.05.115.

[29] W. Tian, H. Li, J. Zhou, Y. Guo, Preparation, characterization and the adsorption characteristics of lignin/silica nanocomposites from cellulosic ethanol residue, RSC Adv. 7 (2017) 41176-41181. https://doi.org/10.1039/c7ra06322a.

[30] J. Cui, H. Sun, X. Wang, J. Sun, M. Niu, Z. Wen, Preparation of siliceous lignin microparticles from wheat husks with a facile method, Ind. Crop. Prod. 74 (2015) 689-696. http://dx.doi.org/10.1016/j.indcrop.2015.05.061.

[31] B. Xue, X. Wang, L. Yu, B. Di, Z. Chen, Y. Zhu, X. Liu, Self-assembled lignin-silica hybrid material derived from rice husks as the sustainable reinforcing fillers for natural rubber, Int. J. Biol. Macromol. $145 \quad$ (2020) 410-416. https://doi.org/10.1016/j.ijbiomac.2019.12.182.

[32] B. Hu, Q. Lu, Y. Wu, Z. Zhang, M. Cui, D. Liu, C. Dong, Y. Yang, Catalytic mechanism of sulfuric acid in cellulose pyrolysis: A combined experimental and computational investigation, J. Anal. Appl. Pyrolysis 134 (2018) 183-194. https://doi.org/10.1016/j.jaap.2018.06.007. 
[33] S. Praneetha, A.V. Murugan, Development of sustainable rapid microwave assisted process for extracting nanoporous Si from earth abundant agricultural residues and their carbon-based nanohybrids for lithium energy storage, ACS Sustain. Chem. Eng. 3 (2015) 224-236. https://doi.org/10.1021/sc500735a.

[34] A. Xing, S. Tian, H. Tang, D. Losic, Z. Bao, Mesoporous silicon engineered by the reduction of biosilica from rice husk as a high-performance anode for lithium-ion batteries, RSC Adv. 3 (2013) 10145. https://doi.org/10.1039/c3ra41889h.

[35] L. Mathur, S.K. Saddam Hossain, M.R. Majhi, P.K. Roy, Synthesis of nano-crystalline forsterite $\left(\mathrm{Mg}_{2} \mathrm{SiO}_{4}\right)$ powder from biomass rice husk silica by solid-state route, Boletín de la Sociedad Española de Cerámica y Vidrio 57 (2018) 112-118. https://doi.org/10.1016/j.bsecv.2017.10.004.

[36] W. Wang, T. Wang, X. Fan, C. Zhang, J. Hu, H. Chen, Z. Fang, J. Yan, B. Liu, Freeze-drying-assisted synthesis of mesoporous $\mathrm{CoMoO}_{4}$ nanosheets as anode electrode material for enhanced lithium batteries, Chem. Res. Chin. Univ. 35 (2019) 261-270. https://doi.org/10.1007/s40242-019-8316-1.

[37] Y. Feng, X. Liu, L. Liu, Z. Zhang, Y. Teng, D. Yu, J. Sui, X. Wang, $\mathrm{SiO}_{2} / \mathrm{C}$ composite derived from rice husks with enhanced capacity as anodes for lithium-ion batteries, ChemistrySelect 3 (2018) 10338-10344. https://doi.org/10.1002/slct.201802353. 
[38] Y. Li, X. Liu, L. Liu, W. Liu, Y. Feng, Y. Guo, Y. Zhu, J. Wang, X. Wang, Coal tar electrode pitch modified rice husk ash as anode for lithium ion batteries, J. Electrochem. Soc. 166 (2019) A2425-A2430. https://doi.org/10.1149/2.0271912jes.

[39] Z. Wen, J. Yang, B. Wang, K. Wang, Y. Liu, High capacity silicon/carbon composite anode materials for lithium ion batteries, Electrochem. Commun. 5 (2003) 165-168. https://doi.org/10.1016/S1388-2481(03)00009-2.

[40] H. Wang, Y. Tang, Artificial solid electrolyte interphase acting as "armor" to protect the anode materials for high-performance lithium-ion battery, Chem. Res. Chin. Univ. 36 (2020) 402-409. https://doi.org/10.1007/s40242-020-0091-5.

[41] Y. Wang, S. Chou, J. Kim, H. Liu, S. Dou, Nanocomposites of silicon and carbon derived from coal tar pitch: Cheap anode materials for lithium-ion batteries with long cycle life and enhanced capacity, Electrochim. Acta 93 (2013) 213-221. http://dx.doi.org/10.1016/j.electacta.2013.01.092.

[42] X. Zhou, L. Xu, X. Liu, J. Zhang, H. Diao, X. Ma, Preparation of monodispersed carbon spheres via hydrothermal carbonization of ascorbic acid and their application in lithium ion batteries, Chem. Res. Chin. Univ. 34 (2018) 628-634. https://doi.org/10.1007/s40242-018-7382-0.

[43] Y. Wu, E. Rahm, R. Holze, Carbon anode materials for lithium ion batteries, J. Power Sources 114 (2003) 228-236. https://doi.org/10.1016/S0378-7753(02)00596-7. 


\section{Pitch\&Graphite}

Lignin
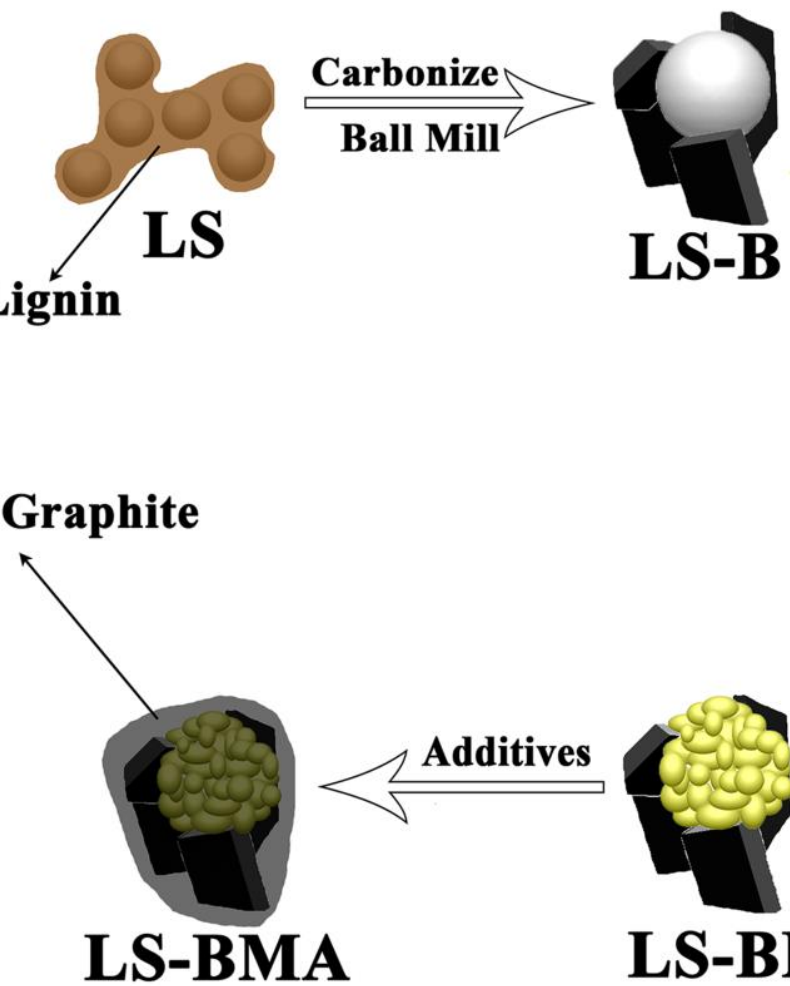

$\mathrm{SiO}_{2}$

- Mg Powder

$\mathbf{S i}$
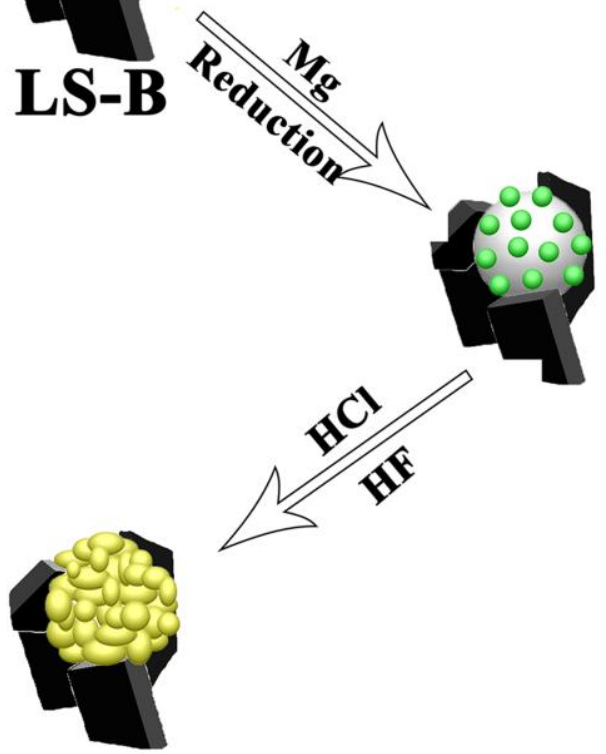

LS-BM

Lignin-derived Carbon

Figure 1. Schematic illustration of the preparation mechanism from LS to LS-BMA.
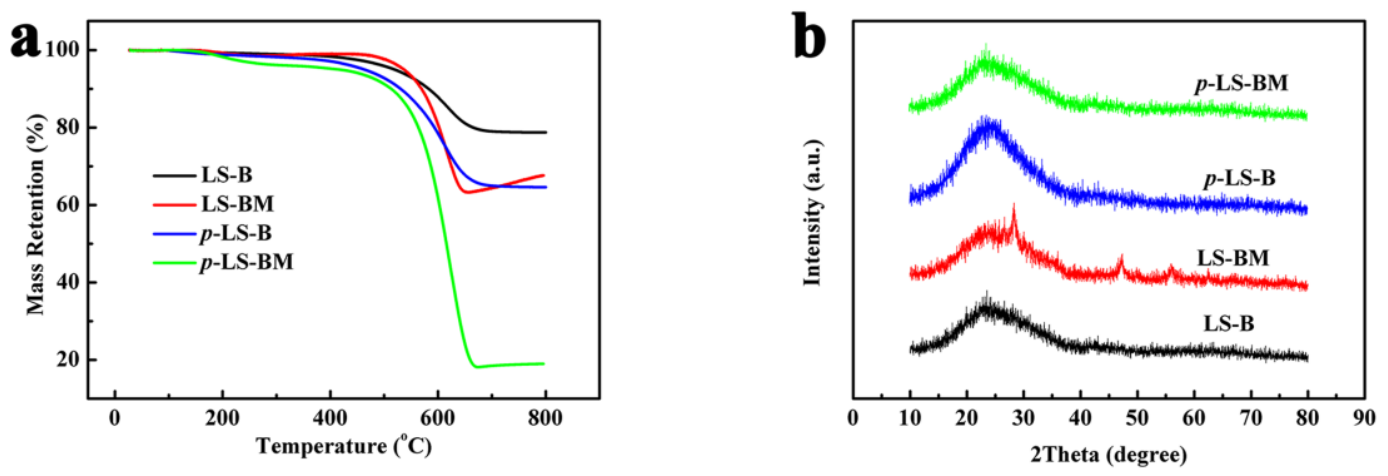

Figure 2. (a) TG curves and (b) XRD patterns of LS-B, LS-BM, $p$-LS-B and $p$-LS-BM. 

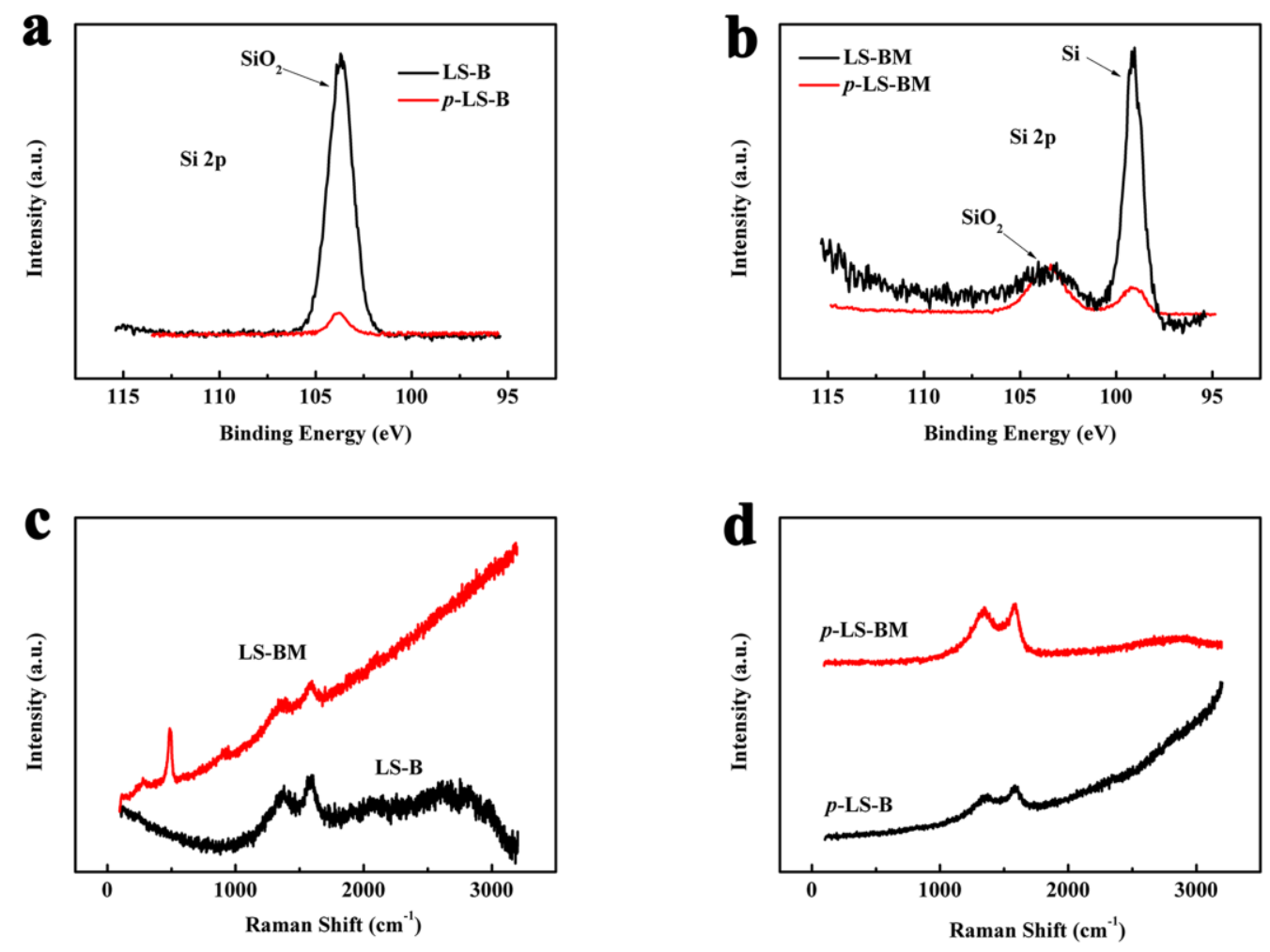

Figure 4. XPS spectra of (a) LS-B and $p$-LS-B; (b) LS-BM and $p$-LS-BM; and Raman 
spectra of (c) LS-B and LS-BM; (d) $p$-LS-B and $p$-LS-BM.
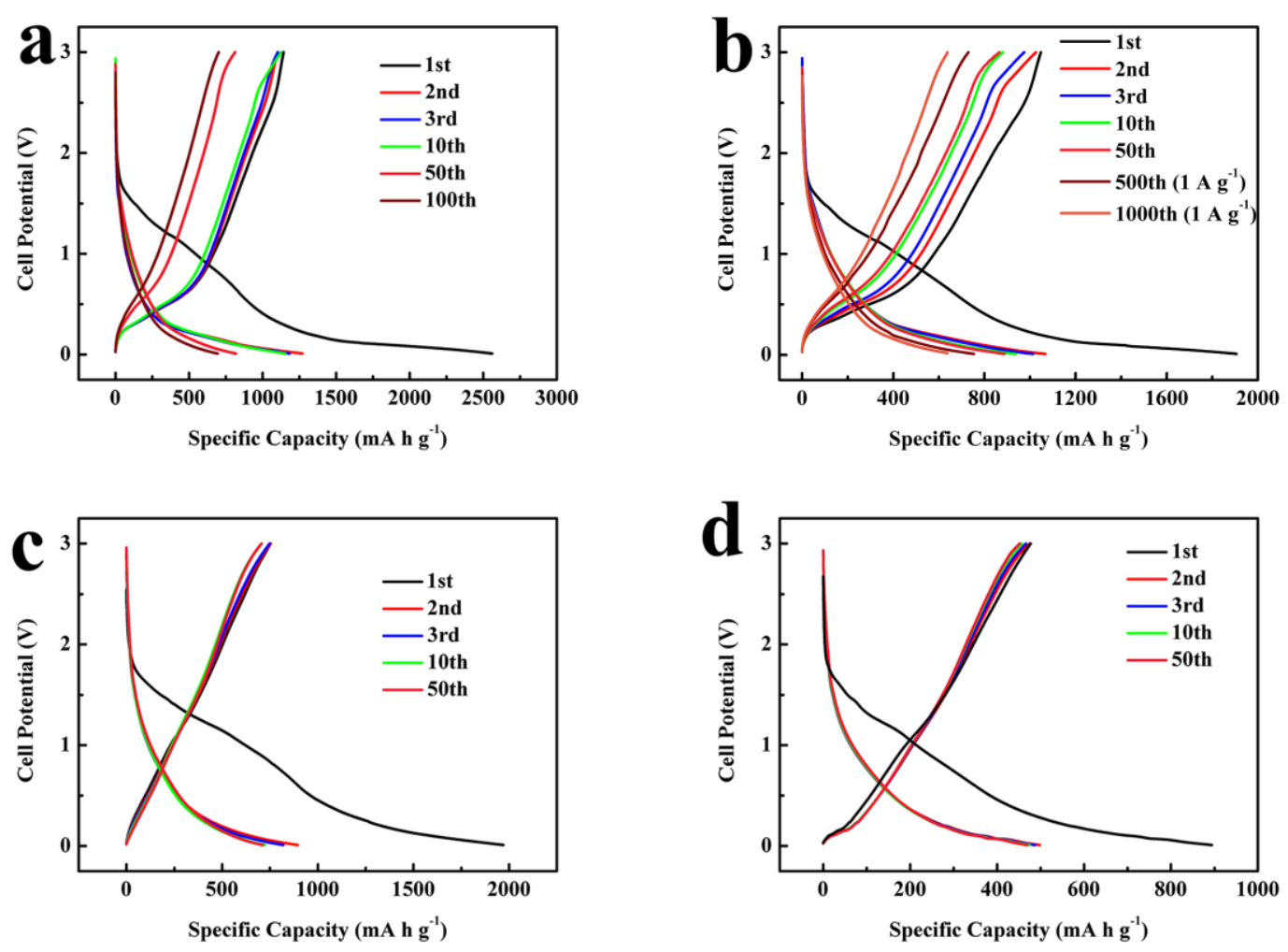

Figure 5. Galvanostatic charge-discharge profiles at $0.1 \mathrm{~A} \mathrm{~g}^{-1}$ of (a) LS-BM; (b) LS-BMA; (c) $p$-LS-BM and (d) $p$-LS-BMA. The data at $1 \mathrm{~A} \mathrm{~g} \mathrm{~g}^{-1}$ exceeding 500 cycles of LS-BMA is contained in (b). 

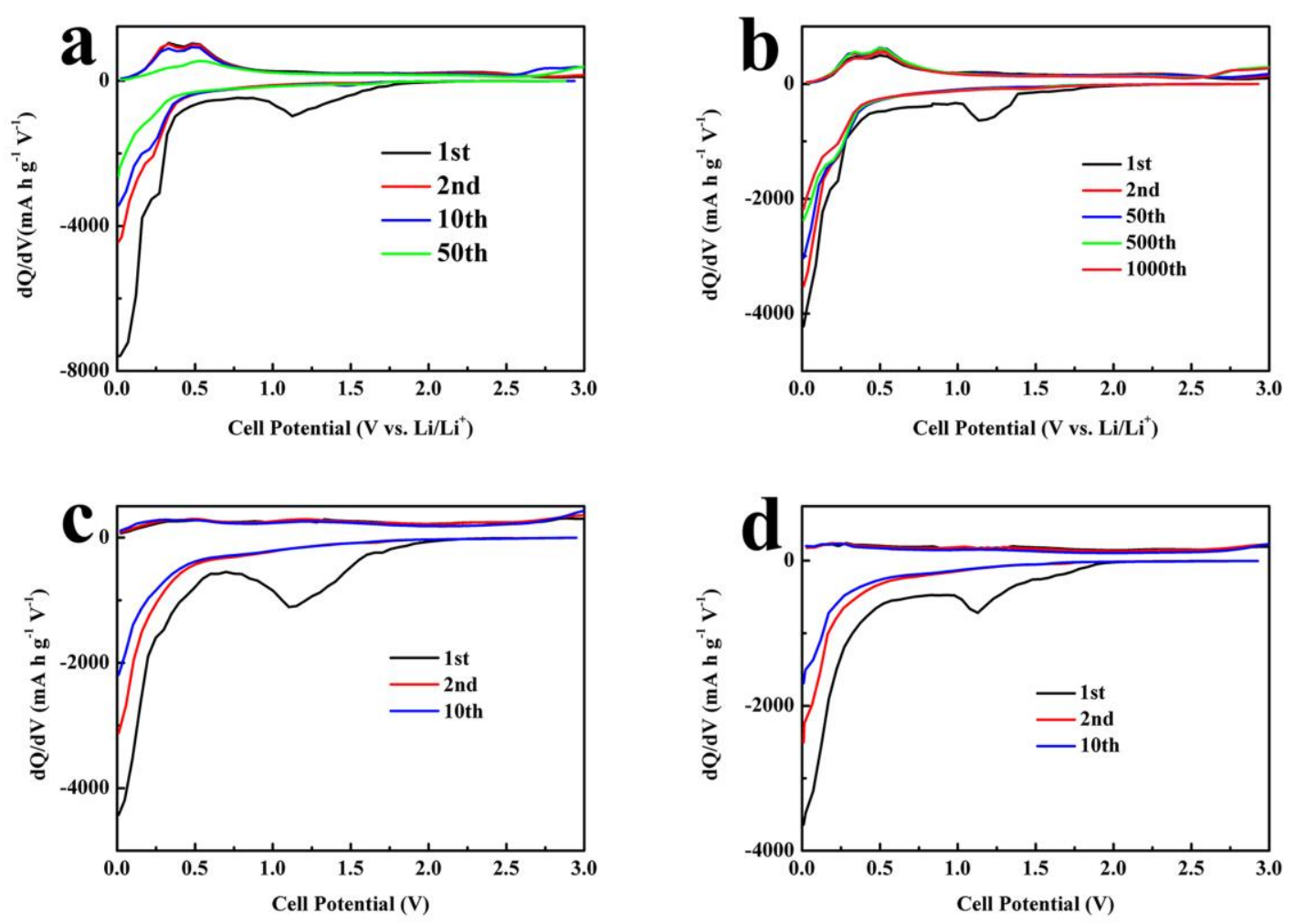

Figure 6. Capacity differential profiles at $1 \mathrm{~A} \mathrm{~g} \mathrm{~g}^{-1}$ of (a) LS-BM; (b) LS-BMA; (c) $p$-LS-BM and (d) $p$-LS-BMA.

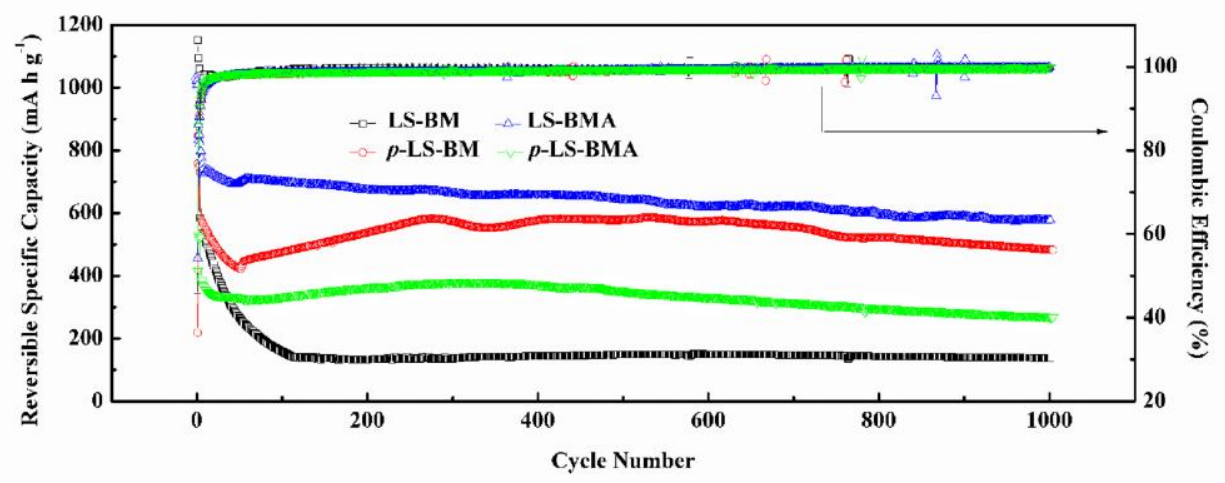

Figure 7. Cycling performance of LS-BM, LS-BMA, $p$-LS-BM and $p$-LS-BMA at 1 A $\mathrm{g}^{-1}$ 


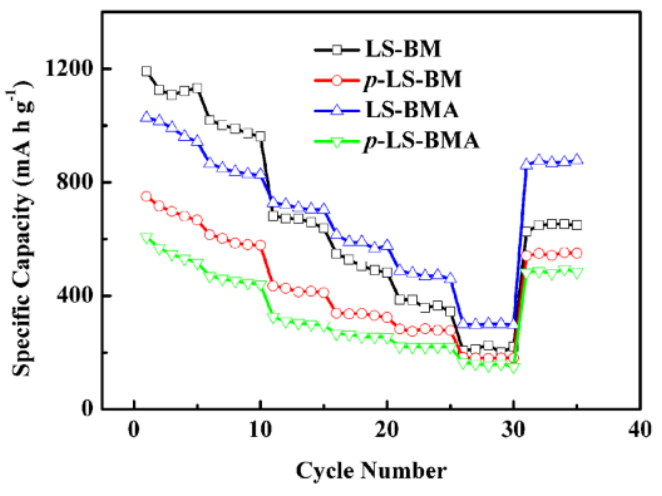

Figure 8 Rate performance of LS-BM, LS-BMA, $p$-LS-BM and $p$-LS-BMA at different current densities from 0.1 to $5 \mathrm{~A} \mathrm{~g}^{-1}$. 


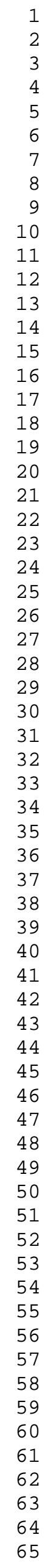


Electronic Supplementary Material

Click here to access/download

Electronic Supplementary Material
Supplementary Information.doc

Electronic Supplementary Materia
Supplementary Information.doc

\section{al

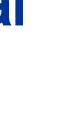

(1)

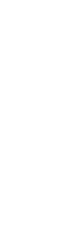

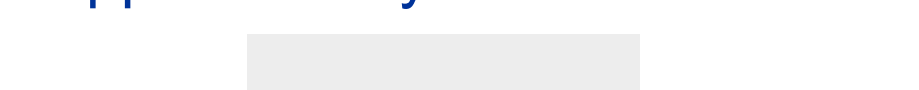

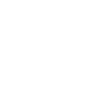

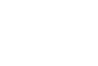

and 

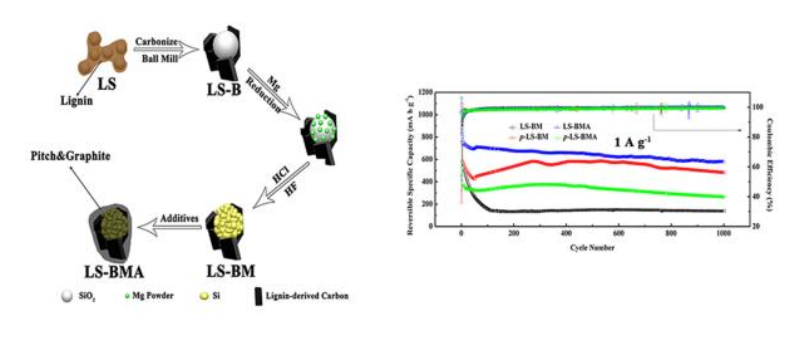

-

. 


\section{Highlights:}

- The biomass derived lignin-silicate composites were utilized into anode materials efficiently.

- The alkaline solution degraded the lignin macromolecules and facilitated magnesiothermic reduction.

- A Si/C anode material with stable cycling performance and high reversible specific capacity was obtained. 